\title{
Advances and prospects in heat pipe: A critical eview
}

\author{
Li-Ping Chen ${ }^{1}$, Li-Peng Yu ${ }^{1}$, Meng-Chao Hao ${ }^{1}$, Yu-Sen $\mathrm{Li}^{1}$ and Qi-Wu Wang ${ }^{1}$ \\ ${ }^{1}$ High-tech Institute, Fan Gong-ting South Street on the $12^{\text {th }}$, QingZhou, ShanDong, 262500, China
}

\begin{abstract}
As an efficient heat transfer element, the heat pipe has excellent thermal conductivity. It has important application value in chemical, building materials, metallurgy, power engineering, bioengineering and other fields. In order to systematically analyze the development trend of heat pipe, the paper takes the literature on heat pipe from 2010 to 2020 included in the Web of Science database as the data source, and analyzes the collected data with information visualization software CiteSpace to draw out the heat pipe technology countries, institutions, research authors distribution network map, showing the technology research power distribution and cooperation in scientific research. The use of software co-occurrence analysis of the hot science and technology of heat pipe technology, at the same time, the key words co-occurrence network diagram and literature citation network are used to analyze the research hotspots, research frontiers and trends of heat pipe technology.
\end{abstract}

\section{Introduction}

R.S.Gaugler, a worker in an Ohio General Motorsin, first put forward the principle of the heat pipe in a U.S. patent in 1944. In 1963, GMGrover of Los Alamos National Laboratory published the first paper in the American Journal of Applied Physics, formally named after it "heat pipe", a heat transfer element relying on the phase change of its internal working liquid. It has advantages of high thermal conductivity, excellent isothermal property, variability of heat flow density, reversibility of heat flow direction, long-distance heat transfer, constant temperature (controllable heat pipe), thermal diode and thermal switch performance and so on, making it become the most effective heat transfer components, heat pipe technology has been widely used in aerospace, military industry and so on. With the continuous improvement of science and technology, the research and application of heat pipe will expand continuously. The development of the new energy, the cooling of chips of the electronic device, the cooling of CPU of laptops, the cooling of highpower transistors, SCR components, circuit control boards, and the efficient heat transfer in the fields of chemical industry, power, metallurgy, glass, light industry, ceramics, the development of high quality equipment will all promote the further development of heat pipe. Aiming to analyze the research power in this field using the information visualization tool of dynamic network analysis, this paper takes the data with the theme of "heat pipe" included in the core collection of Web of Science as a sample to determine the research hotpots, research frontiers and development trends in the field of heat pipe technology.

\section{Data source and research method}

\subsection{Data source}

Web of Science core collection citation database was adopted in Thomson Reuters' search platform. Each data record mainly includes the author, title, abstract and citation of the document. Taking "heat pipe" as the subject term, papers published between 2010 and 2020 was searched, and 3193 papers were obtained, including 36136 citations (retrieved on August 10, 2020). In the econometric analysis, the year $2010-2020$ is divided into 11 time periods with 1 year as the unit.

\subsection{Research methods}

These data was analyzed using CiteSpace information visualization software, CiteSpace itself can directly convert the data format downloaded from the internet, without the need of converting the downloaded original document data to the correlation matrix[1]. In addition, drawing a co-citation network map is an important part of citation analysis. Among them, an important aspect we need to face is to perform cluster analysis on co-citation network maps. In the co-citation network, the connection of co-citation means that two documents are cited by another document simultaneously, and the co-citation strength between two documents is a measure of the cocitation frequency between documents. Therefore, in the co-citation network graph, the maximum expected cluster analysis can be carried out through indicators such as the centrality of the document node and the citation frequency. CiteSpace information visualization software can be used to detect and analyze the changing trends of the research 
frontiers of disciplines over time and the relationship between the research frontiers and their knowledge base, and to discover the internal connections between different research frontiers. By visualizing the literature information in the subject field, researchers can intuitively identify the evolution path of the subject frontier and the classic basic literature in the field of the subject.

\section{Analysis of scientific research cooperation}

Scientific research cooperation can be divided into three perspectives: cooperation between countries and regions, cooperation between institutions, and cooperation between authors, the academic cooperation was analyzed from the macro, middle and micro perspectives, and simultaneously, it analyzes the countries or regions, institutions, and author groups involved in the selected documents by drawing a cooperation map, and further analyzes the author group to highlight the core authors. The size of the groups in the cooperation map indicates the number of published papers. The line reflects the degree of the cooperation.

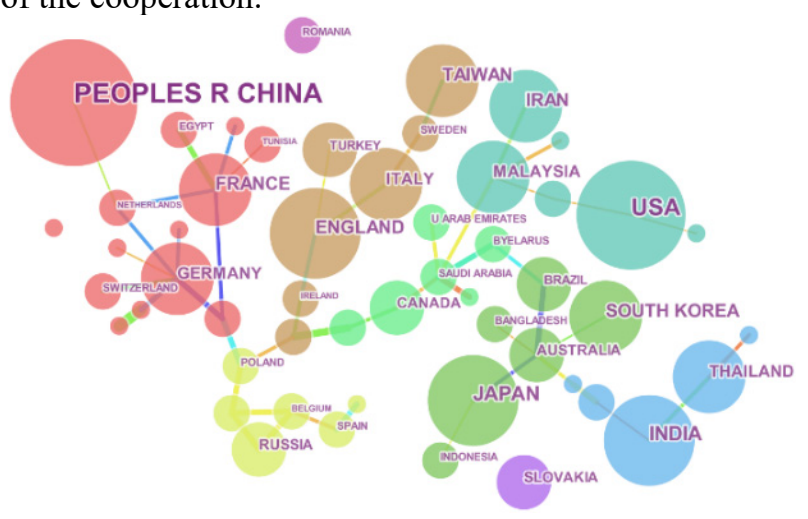

\subsection{Analysis of cooperation between countries/regions}

The cooperation between different countries or regions is shown in Figure 1, from which we can see that researches of heat pipe technology comes from multiple countries (regions), China, the United States, India, Japan, and the United Kingdom are the main countries in which papers are published in this field, ranking the top five in the world. In the top five, there are few connections between countries, which shows that there is little cooperation between countries.

\subsection{Analysis of cooperation among scientific research institutions}

The cooperation between institutions is shown in Figure 2, from which we can seen that the top ten institutions according to the node size are the Chinese Academy of Sciences, South China University of Technology, Shanghai Jiaotong University, University of Missouri, University of Science and Technology Beijing, University of Nottingham, University of Zilina (Slovakia) Republic of China), University of Science and Technology of China, Beijing University of Aeronautics and Astronautics, and National Taiwan University. Seven of the top ten institutions are Chinese scientific research institutions, which shows that Chinese scientific research institutions are the main research institutions in the field of heat pipe technology. As is vividly shown in the figure, the leading scientific research institutions have formed small clusters centered on themselves, which makes them form relatively close cooperative relations.

Figure 1. Cooperation graph of country.

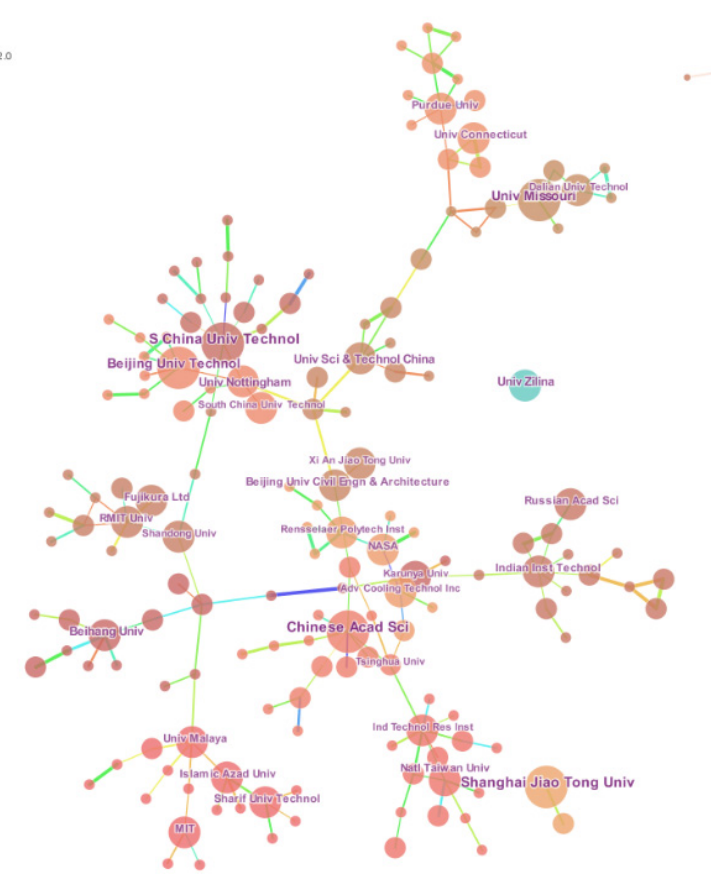

Figure 2. Cooperation graph of institution

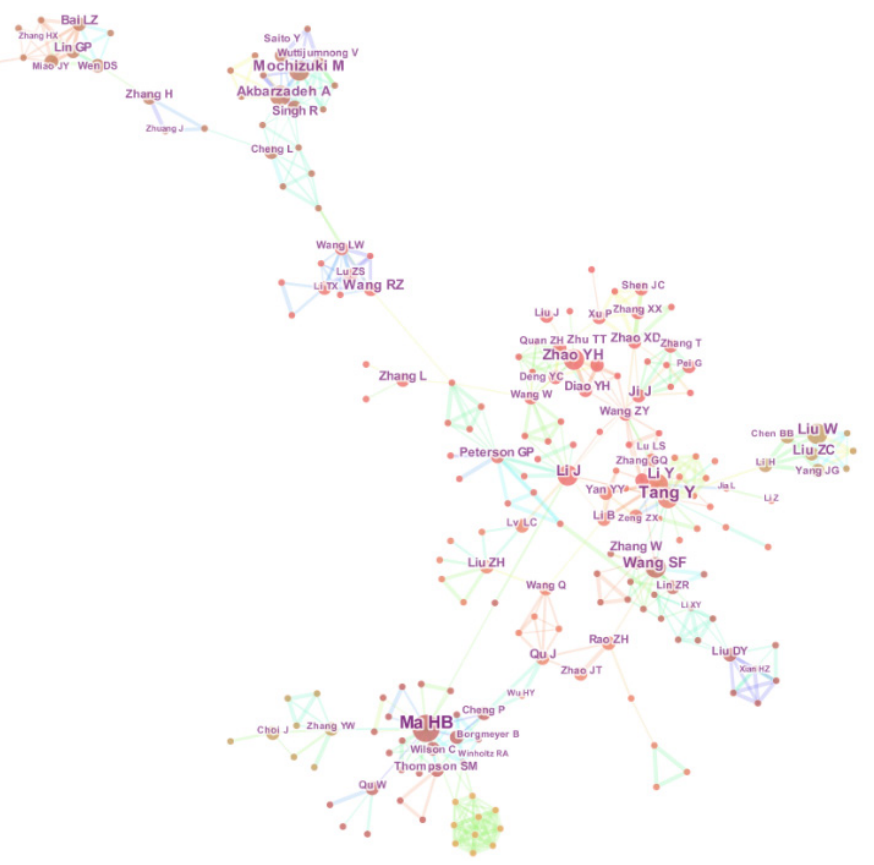

Figure 3. Cooperation graph of author 


\subsection{Analysis of cooperation among authors}

As is shown in Figure 3, the top five authors in terms of the amount of published papers are: Ma HB (University of Missouri), Tang Y (South China University of Technology), Malcho M (University of Zilina), Wang SF (South China University of Technology) and Zhao YH (University of Science and Technology Beijing), which formed many small clusters with core authors as the center, and the small clusters are scattered, indicating that researchers in heat pipe technology research have formed a cooperative team with core authors as the center mostly through institutions or projects cooperation in groups.

\subsection{Analysis of the cooperation of scientific research}

As is shown in Table 1, the top ten countries, institutions and authors with regard to papers being published is summarized, which points out the betweenness centrality of countries and research institutions. In the analysis of the graph generated by the Citespace visualization software, the nodes with betweenness centrality greater than or equal to 0.1 are defined as key nodes. The betweenness centrality of a node refers to the number of nodes passing through all the shortest paths in the network, which is a measure of the size of the nodes in the network connected in the overall network. The higher the betweenness centrality of a node, the more it appears on the shortest path in the network, the greater its influence and importance [2].

Table 1. The ranking of the number of literatures and betweeness centrality of countrtries, institutions and authors.

\begin{tabular}{cccccccc}
\hline Rank & Country & Centrality & Country & Rank & Institution & Rank & Author \\
\hline 1107 & CHINA & 0.38 & GERMANY & 87 & Chinese Acad Sci & 62 & Ma HB \\
629 & USA & 0.33 & USA & 81 & S China Univ Technol & 46 & Tang Y \\
169 & INDIA & 0.29 & FRANCE & 77 & Shanghai Jiao Tong Univ & 30 & Malcho M \\
159 & JAPAN & 0.24 & ENGLAND & 72 & Univ Missouri & 28 & Wang SF \\
148 & ENGLAND & 0.19 & PEOPLES R CHINA & 62 & Beijing Univ Technol & 27 & Zhao YH \\
137 & SOUTH KOREA & 0.12 & JAPAN & 40 & Univ Nottingham & 27 & Li J \\
136 & TAIWAN & 0.08 & INDIA & 40 & Univ Zilina & 25 & Mochizuki M \\
119 & FRANCE & 0.08 & CANADA & 35 & Univ Sci \& Technol China & 24 & Liu W \\
112 & IRAN & 0.07 & AUSTRALIA & 34 & Beihang Univ & 24 & Shafii MB \\
86 & GERMANY & 0.07 & CROATIA & 33 & Natl Taiwan Univ & 22 & Faghri A \\
\hline
\end{tabular}

In brief, countries engaged in heat pipe technology research at present are distributed all over the world, but the cooperation among them is scattered, and a global cooperation network has not yet formed. There are several research groups, the authors mainly carry out cooperation through institutions, and the top three countries in terms of the amount of published papers are China, the United States and India. China published the largest amount of papers, with a large number of research institutions and scientific researchers, but there is little cooperation between them. Authors mainly cooperate with research institutions and scientific research teams, and China's betweenness centrality ranks fifth. Therefore, the number of Chinese publications is far ahead, but the overall influence is relatively low, and cannot occupy a dominant position in the research of heat pipe technology. The U.S. ranks second in terms of the number of publications and second in betweenness centrality, which is kind of influential.

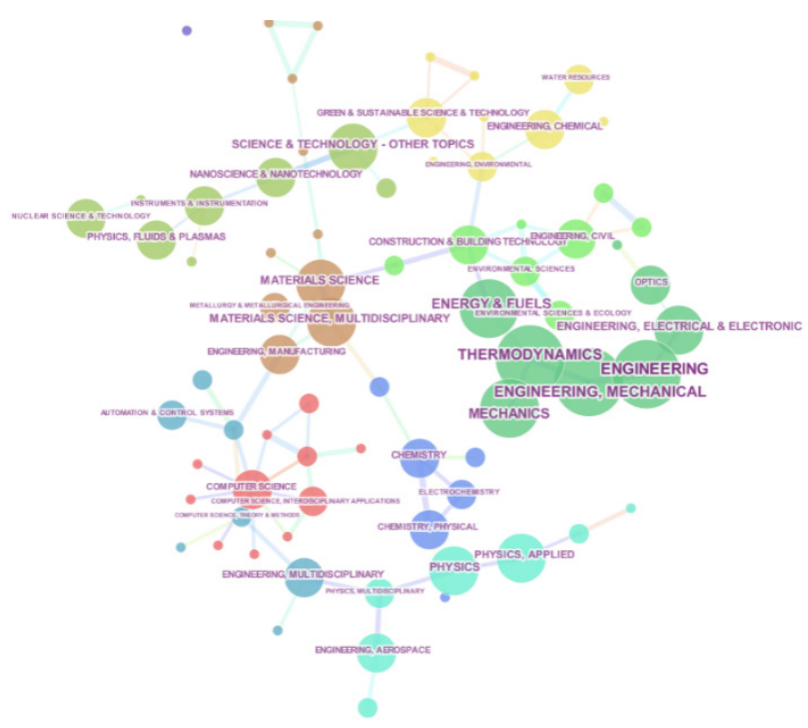

Figure 4. Co-occurrence graph of research fields.

3.4.1 An example. In this example we can see that there are footnotes after each author name and only 5 addresses; the 6th footnote might say, for example, 'Author to whom any correspondence should be addressed.' In addition, acknowledgment of grants or funding, temporary addresses etc might also be indicated by footnotes[5]. 


\section{Analysis of the research field}

Through software occurrence analysis, we obtained hot scientific areas of heat pipe technology, which is as shown in Figure 4. 78 fields are involved in heat pipe technology, covering a very wide range, and mainly concentrated in engineering, thermodynamics, engineering machinery, mechanics, energy and fuel, physics and materials. Among these, engineering is at the core position, which shows that heat pipe technology has a huge development potential in the field of engineering. The application of heat pipe technology to engineering practice gives full play to the characteristics of heat pipe technology, solves problems in actual engineering, and develops and explores new efficient heat and mass transfer, which transforms some traditional equipment, and improves the safety, reliability and efficiency of the system.

\section{Analysis of the latest development of heat pipe technology}

\subsection{Analysis of research hotpots}

Research hotpots refer to one or more research topics that researchers are concerned about in a certain research field, and Citespace co-word analysis can reflect the overview of the hotpot of the target field. By extracting keywords in the literature, analyzing hot pipe technology research hotpots from 2015 to 2020, a keyword co-occurrence network map was drawn, the size of the node in the graph reflects the frequency of the keyword, and the black font indicates the common key words of different documents, "\#number" represents the cluster words named after the common keywords extracted using the LLR algorithm, and each color block indicates a cluster composed of various documents with similar research topics. Through the clustering of keywords, 11 research topics are obtained. The phenomenon of crossing between clusters indicates that there is a crossing of research topics between these clusters, and there are relatively close relationship between them. Color blocks that do not cross other clusters indicates that this type of topic has a relatively independent nature.

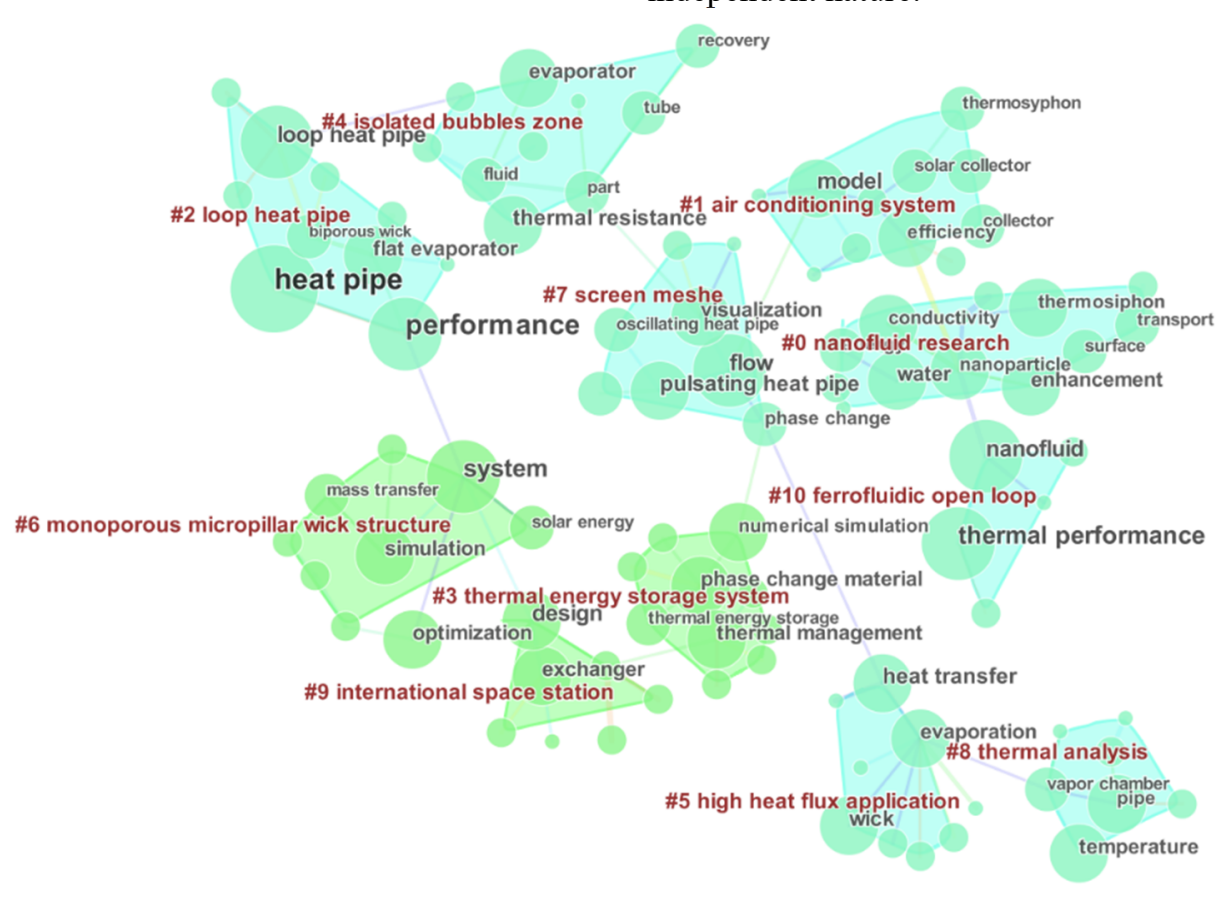

Figure 5. Co-occurrence graph of keywords.

As is vividly shown in Figure 5, in addition to the searched subject term "heat pipe", "performance", "thermal performance", "system", "loop heat pipe", "flow", "model", "heat transfer", " "Nanofluid", "design" and "pulsating heat pipe" appear frequently, which in a certain degree reflection the research hotpots of reactive heat pipe technology are concentrated on loop heat pipes, nanofluids, pulsating heat pipes, heat transfer performance of heat pipes and so on.

Table 2 shows the clustering of keywords gained through automatic clustering and with higher correlation.

Table 2. Keyword clustering table.

\begin{tabular}{ccccc}
\hline ClusterID & Size & Silhouette & mean(Year) & Label (LLR) \\
\hline 0 & 13 & 0.935 & 2012 & Nanofluid research
\end{tabular}




$\begin{array}{cccc}1 & 11 & 0.912 & 2012 \\ 2 & 10 & 0.911 & 2013 \\ 3 & 10 & 0.843 & 2014 \\ 4 & 10 & 0.852 & 2012 \\ 5 & 9 & 0.925 & 2013 \\ 6 & 9 & 0.947 & 2013 \\ 7 & 8 & 0.814 & 2012 \\ 8 & 7 & 0.961 & 2013 \\ 9 & 7 & 0.908 & 2014 \\ 10 & 5 & 0.957 & 2013\end{array}$

Number the clusters in the form of "\#0,\#1..." etc. (Cluster ID). The smaller the cluster number, the larger the number of classic documents (Size) in the cluster. The Silhouette value represents how close these classic documents are. Mean (Year) represents the average year, which can reflect the timeliness of the documents in the cluster. Top Terms is the cluster name named by the LLR algorithm. The cluster named based on the LLR algorithm can objectively reflect the hotpots in the field of heat pipe technology from 2010 to 2020 . The above clustering can be categorized into four aspects: nanofluid research, new heat pipes, applications of heat pipe, and research of the performance of the heat pipe performance.

Because the heat pipe transfers heat using the phase change of the working fluid, the selection of the working fluid is of vital significance important for improving the thermal performance of the heat pipe. Nanofluids can enhance heat transfer, and the heat transfer performance of the heat pipe can be enhanced by applying various nanofluids to heat pipes as working fluids.

At present, the research on the application of nanofluids to heat pipes can be divided into three types. The first is a heat pipe with microgrooves, meshes and sintered metal porous materials that provide capillary force, which belongs to convective evaporation and convective condensation of liquid film. Boiling heat transfer may occur under high heat fluxes in heat pipes with microgrooves, but does not occur in mesh and sintered metal heat pipes, such as ordinary cylindrical heat pipes, flat axial heat pipes, and capillary pump circuits (CPL). The second type is pulsating heat pipe [3]. The heat transfer of this kind of pipe is realized through the phase change and the oscillation of the liquid plug. During the whole process, there is no need to consume external mechanical and electrical power, and is completely selfoscillation driven by heat [4]. The third type is a closed two-phase thermosyphon, the heat transfer mechanism of which is similar to steady-state nucleate boiling, and the driving force of fluid flow is the buoyancy generated by the boiling two-phase flow.

\subsection{Analysis of the Research Frontier}

The founder of scientometrics, Price first put forward the concept of "research frontier", which is a collection of highly cited and time-sensitive documents in the scientific citation network, from his perspective, the research frontier can dynamically reflect the essence of a research

Air conditioning system
Loop heat pipe
Thermal energy storage system
Isolated bubbles zone
High heat flux application
Monoporous micropillar wick structure
Screen meshe
Thermal analysis
International space station
Ferrofluidic open loop

field [5].

Garfield defined the research frontier as a core set of highly cited papers, believing that the name of the research frontier can be extracted from the words or phrases appearimg most frequently in the title of papers[6] Chen Chaomei believed that the research frontier is a set of timely, dynamic and potentially research-worthy questions, and the knowledge base of the research front is citation and co-citation traces[7]. The analysis of the research frontier of this paper is mainly reflected by the document network relationship of Cited Reference, and the research frontier and development trend of heat pipe technology were analyzed by drawing the document cocitation network graph.

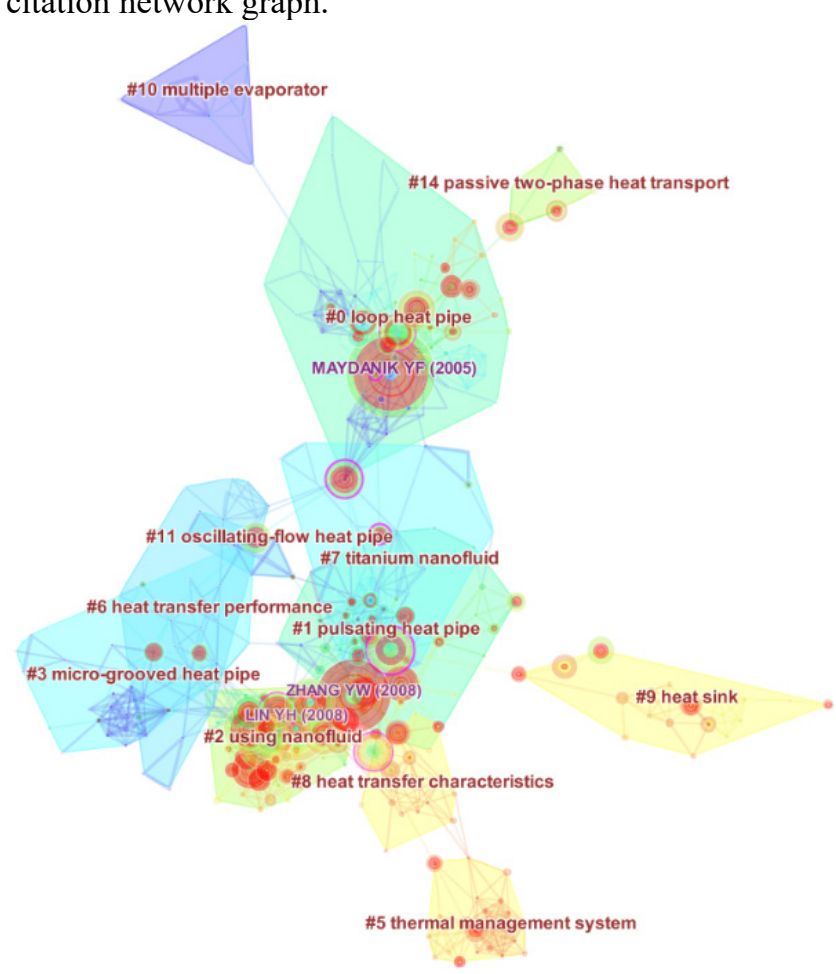

Figure 6. Cluster view of the research frontier of heat pipe technology.

As is vividly shown in Figure 6, 14 research topics are obtained after clustering the co-cited documents. After excluding clusters with less correlation, the clusters are numbered in the form of "\#0,\#1...", and the smaller the cluster number is, the more documents are clustered. The clustering of co-cited documents is shown in Table 3. 
Table 3. Clustering table of co-cited documents.

\begin{tabular}{ccccc}
\hline ClusterID & Size & Silhouette & mean(Year) & Label (LLR) \\
\hline 0 & 79 & 0.95 & 2005 & loop heat pipe \\
1 & 50 & 0.81 & 2004 & pulsating heat pipe \\
2 & 49 & 0.859 & 2009 & using nanofluid \\
3 & 33 & 0.904 & 2003 & micro-grooved heat pipe \\
5 & 22 & 0.939 & 2014 & thermal management system \\
6 & 21 & 0.925 & 2003 & heat transfer performance \\
7 & 20 & 0.92 & 2003 & titanium nanofluid \\
8 & 18 & 0.88 & 2012 & heat transfer characteristics \\
9 & 18 & 0.991 & 2012 & heat sink \\
10 & 12 & 0.994 & 2002 & multiple evaporator \\
11 & 7 & 0.993 & 2002 & oscillating-flow heat pipe \\
14 & 6 & 0.997 & 2008 & passive two-phase heat transport
\end{tabular}

The cluster name based on the LLR algorithm can objectively reflect the frontier issues in the field of heat pipe technology research. The following is a detailed introduction to several representative frontier issues.

5.2.1 Loop heat pipe [8]. As an efficient two-phase heat transfer device, the loop heat pipe (LHP) has attracted more and more attention due to its high heat transfer efficiency, small temperature difference, and longdistance heat transfer characteristic. The most significant difference between LHP and traditional heat pipes is the localized setting of the capillary structure. The capillary wick is only located in the evaporator, which separates the capillary suction function of the traditional heat pipe capillary wick from the liquid return function. For LHP, the liquid flows back through the smooth inner wall pipeline, which significantly reduced the flow pressure drop. Therefore, the micron-sized pore capillary core that can provide high capillary pressure can be used to overcome the influence of gravity without the negative influence of increasing the liquid return resistance. Therefore, the LHP has a long heat transfer distance and strong anti-gravity ability, which solves the problem of the traditional heat pipe that it is limited by the usage direction and length. Furthermore, the LHP separates the vapor and the liquid channel, which are transmitted in their respective pipelines, thereby preventing the occurrence of carryover. It is worth mentioning that the separation of the vapor pipeline and the liquid pipeline makes the installation of the LHP flexible and convenient, and is no longer limited by the position and distance of the heat source and the heat sink, which is another advantage over the traditional heat pipe.

There are many factors affecting the operation of the loop heat pipe. As the core component, the characteristic parameters of the capillary core directly affect the heat transfer performance of LHP. The capillary wick is the core element of the evaporator, it provides the circulating power of the working fluid, provides the liquid evaporation interface and realizes the liquid supply, and simultaneously, it prevents the vapor generated outside the capillary wick from entering the reservoir. Therefore, the performance optimization for LHP mainly focuses on the improvement of the capillary wick. The most common technology for manufacturing capillary wicks is "Sintering of the metal powder", the biggest disadvantage of which is that the internal structure of the capillary wick is random, causing uneven heat transfer. J.Esarte et al. [10] manufactured capillary cores using 3D laser printing SLM (Selective Laser Melting) to solve this problem, which can completely control the geometric size of the capillary core channel, aiming to achieve the best design effect according to the specified requirements, however, the cost of this method is relatively high and is limited by the pore size and suitable materials.

Currently, capillary cores with a variety of structures and materials have been put into application, such as wire mesh [11-13], foam metal [14], polyethylene [15], ceramic core [16], metal powder sintering [17-19]. However, most of the above-mentioned capillary wicks have a singlescale structure, if the pore size is too large, the driving force of the capillary will be insufficient, and if the pore size is too small, it will lead to excessive resistance of vapor overflow, and it is difficult to coordinate the contradictory relationship between vapor overflow and liquid intake.

There are different pore sizes of the multi-scale capillary wicks on the same surface. Smaller pores are used for liquid inhalation, and larger pores are used for vapor overflow, which shows great advantages in solving the different requirements of capillary wicks for pore sizes and has been gradually applied to LHP [20-22]. Moreover, to meet the different requirements of the capillary wick for high-efficiency evaporation and suppression of heat leakage, composite capillary wicks have become a new trend in the development of capillary wicks, the production processes of which includes bimetal sintering $[23,24]$ and the addition of pore formers [25]. In real application of LHP, in addition to its own structure, factors such as the ambient temperature and placement angle of the LHP condensing end will also 
affect its heat transfer characteristics due to seasonal changes and changes in the working environment. Currently, the research work on the multi-scale composite capillary core has not been carried out systematically, and the optimization mechanism of LHP is still under exploration.

\subsubsection{Pulsating heat pipe, Oscillating-flow heat pipe.} The pulsating heat pipe is a new type of high-efficiency heat transfer element proposed by Akachi in the early 1990s, which can be used in small spaces and high heat flux conditions. It has the advantages of small size, simple structure, and good performance in terms of heat transfer, therefore, it gains the general attention from scholars. Compared with traditional heat pipes, the structure and operation mechanism of the pulsating heat pipe have the following advantages: (1)Small size, simple structure, and low cost. The small pipe diameter determines it a small overall size and does not require a liquid wick, which reduces the complexity of the heat pipe structure and production costs; the oscillation power is driven from the oscillating heat pipe itself, without other auxiliary equipment, and has low costs in terms of operation and maintenance. (2) Good heat transfer performance. In addition to heat transfer through phase change, the pulsating heat pipe also transfers sensible heat through gas-liquid oscillation and converts the heat into work required for oscillation. (3) Good flexibility. The shape of the pulsating heat pipe can be bent arbitrarily, there can be multiple heating and condensing sections, and the parts being heated and condensed can be selected arbitrarily, and it can work at any tilt angle and heating mode, which greatly enhances the adaptability of the pulsating heat pipe, making it applied to more areas. All of these advantages mentioned above determine that the pulsating heat pipe has great potential in solving the problem of high heat flux density in small spaces, developing high-efficiency heat exchangers and refrigeration equipment and realizing temperature control technology under changing gravitational field conditions.

Currently, the research of pulsating heat pipe technology is mainly in the experimental stage, and it is a common research method to observe the flow pattern and flow direction in the pipe when the pulsating heat pipe starts and runs stably through visual experiments.

Tong et al. [26] carried out visualization experiments using ethanol as the working fluid and a polyethylene pipe with an inner diameter of $1.8 \mathrm{~mm}$ to form a loop pulsating heat pipe with 7 elbows. It was found that when the pulsating heat pipe started, the working fluid boiled, and then a stable state of the vapor-liquid plug phase was formed, and there was a minimum starting heat load, making the fluid circulate in a fixed direction. Khandeka et al. [27] and Zhang et al. [28] also observed that during the movement of the liquid plug in the tube, the working fluid formed a liquid film on the tube wall. Yang W et al. [29] considered that the violent expansion of bubbles in the heating section was a typical phenomenon in a pulsating heat pipe.

Through visualization experiments, Qu Wei et al. [30],
Yang $\mathrm{H}$ et al. [31], and Cao X et al. [32] all found that when the input heat was low, there was basically plug-like flow in the tube, and the fluid could only oscillate in a small range in a partial area and the heat transfer performance was poor. However, the fluid oscillation amplitude increased as the heat flow density increased, and the flow pattern in the tube gradually changed from plug flow to annular flow, making the heat transfer performance greatly improved. $\mathrm{Xu} \mathrm{R}$ et al. [33] also observed that in the process of pulsating heat pipe from startup to stable operation, the flow pattern of the working fluid would experience changes from bubbly flow, slug flow, plug flow to stirring flow.

In summary, as the heating power of the pulsating heat pipe increases the evaporation of the working fluid, and the working quality of the condensed reflux also increases, going through the start-up stage to the stable oscillation stage. The working fluid in the tube changed from a simple wall back flow to a violent circulating flow, the flow pattern changed correspondingly, which gradually enhanced the heat transfer performance, and there are usually the generation, growth, separation and merging of bubble appearing in the evaporation section, and the condensation, disappearance of bubbles and the merging of small bubbles appearing in the condensation section.

Qu et al. [34-36] formulated a silicon-based microloop pulsating heat pipe using the MEMS wet etching process with a trapezoidal cross-section channel and an equivalent diameter of $251-394 \mu \mathrm{m}$, and carried out experimental study in terms of its visualization and heat transfer characteristics. Taking FC-72 and R113 as the working fluids, bubbly flow, plug flow, annular/semiannular flow, we observed wave annular flow and jet flow[35], proving that the size of the pulsating heat pipe can still operate normally after miniaturization, and shows good heat transfer performance [36]. After studying the pulsating heat pipe of silicon-based micro loop with equivalent channel diameter of $571 \mu \mathrm{m}$, Youn and Kim [37] found that the effective thermal conductivity of the heat pipe could reach $600 \mathrm{~W} /(\mathrm{m} \cdot \mathrm{K})$ when ethanol was filled in. The above research has laid the foundation for the development of miniaturization and integration of loop pulsating heat pipes.

Due to the difference in scale effect, interface characteristics, and dominant forces, the phase change thermal behavior of the working fluid inside a micro-loop pulsating heat pipe with a channel equivalent diameter of only a few hundred microns is more complicated than that of a conventional pulsating heat pipe. The related research is still in its infancy and needs to be investigated systematically subsequently. The future research direction is the diversification, miniaturization and practicality of pulsating heat pipes.

5.2.3 Nanofluid. In 1995, Choi et al. [38] of the U.S Argonne National Laboratory proposed to prepare a new type of heat exchange medium "nanofluid" by adding nano-scale metal or non-metal oxide particles to the heat exchange medium. Because the thermal conductivity of metals and their oxides is much greater than that of liquids, and the small size and strong surface effects of 
nanoparticles enable them to be stably dispersed in liquids, the heat transfer performance of the heat transfer medium is greatly improved, simultaneously it avoided undesirable consequences such as pipeline blockage caused by the sedimentation of traditional micron-level material additives.

J.M.Wu et al. [39] reviewed the research on nanofluid heat transfer and critical heat flux density, and proposed the challenges and research directions of nanofluids in the future, they pointed out that the current experimental data of the thermal properties of nanofluids were neither sufficient nor reliable for engineering applications, and the results of different researchers were not consistent, which made the basic mechanism of the heat transfer phenomenon still uncertain. There are still huge challenges in the application of nanofluids in the industrial field. First of all, the long-term physical and chemical stability of nanofluids is one of the biggest challenges affecting the commercialization of nanofluids, but the production of stable nanofluids with non-agglomerated nanoparticles was still a laboratory-scale research. In addition, the reason why nanofluids have high heat transfer characteristics is still under debate. It is necessary to study the surface and interface effects, the interaction of nanoparticle motion, static and dynamic conditions, particularly, to determine the basic principles of nanofluid flow and heat transfer. So that the application of nanofluids can be reliably realized. Therefore, the future research directions of nanofluids are as follows:

- $\quad$ Study the stability of nanofluids under static and dynamic conditions, and determine whether nanofluids can be successfully applied in engineering systems that require stable thermal management.

- Under the context of global cooperation, establish a nanofluid database, including the size of thermophysical properties of nanoparticle, distribution and detailed characteristics of additives or stabilizers, and priority should be given to nanofluids with potential when using it.

- Carry out more experiments and numerical studies with regard to the interaction between suspended nanoparticles and the boundary layer to reveal the mechanism of nanofluids intensifying convective heat transfer.

- Experimental and numerical study should be carried out for the bubble dynamics of boiling nano fluids, in which the effects of surface tension, nano particles and additives are considered, so as to determine the effect of solid surface modification and suspended nano particles on the enhancement of CHF in boiling heat.

5.2.4 Micro-grooved heat pipe. Li X et al. [40] constructed micro heat pipe capillary limit models with dovetail, rectangular, trapezoidal and V-shaped groove micro structures respectively. When the groove depth was $0.2-0.3 \mathrm{~mm}$ and the depth ratio was $1.2-1.5$, micro heat pipe with small angle dovetail groove (sector structure), rectangular and small angle trapezoidal groove structure could obtain better heat transfer performance. Y.M. Hung et al. [41] studied the influence of different cross-sectional geometries of micro-grooved heat pipes on heat transfer performance. Comparing the star-shaped groove and the orthogonal polygonal micro-grooved heat pipe, and the factors of heat transfer enhancement due to the change of geometric parameters were determined. J.Ha et al. [42] and V. Sartre et al. [43] also studied aluminum/ammonia triangle MHP. Balram Suman et al. [44] studied the effect of surface tension gradient on the performance of microgrooved heat pipes, finding that the effect of surface tension gradient increased with the increase of the corner angle of the polygonal heat pipe. The change of liquid temperature and surfactant concentration have an undesirable effect on the surface tension gradient. However, the surface tension gradient can be increased using a suitable surfactant, which is beneficial for the liquid flow in the heat pipe and the acquisition of surface charge, so as to improve the performance of the micro heat pipe.

Since Cotter et al. proposed a more complete theory of micro thermal management in 1965 [45], micro heat pipes have experienced the development of single micro heat pipes, heat pipe arrays and micro flat heat pipes. The research hotpots in recent years are mainly focused on the heat transfer characteristic model of the flat micro heat pipe and the structure of the micro heat pipe; V.Sartre et al. [43] established a 3D model of a heat pipe array with triangular micro channels and analyzed its performance with regard to flow and heat transfer; Gillot et al. [46] established a structural model for calculating the heat transfer limit of a rectangular channel micro heat pipe;

Liu Y et al. [47] established a mathematical model for the flow and heat transfer process inside a flat heat pipe with a rectangular channel. Research on the micro channel structure design, processing and manufacturing, numerical simulation and experimental observation of heat and mass transfer behavior in the tube have also been constantly deepened[48]. Kang et al. designed star-shaped and diamond-shaped micro-channel heat pipes with multiple sharp corners; Tang Q et al. [49] conducted a detailed experimental study on a new type of zero-cut-angle curved flat micro heat pipe; Fan $\mathrm{C}$ et al. [50] found that gravity has a significant effect on the axial liquid film distribution of the heat pipe; Li W et al. [51] analyzed the influence of the depth of the rectangular channel on the heat transfer characteristics of the flat micro heat pipe, and found that the deeper the micro channel, the better the heat transfer performance of the micro heat pipe; the performance of the heat transfer of the micro heat pipe with unequal width channels is better than that with equal width channels; $\mathrm{Li}$ $\mathrm{X}$ et al. [52] carried out experiment on the start-up and heat transfer performance of micro-channel pulsating heat pipes under vertical and horizontal placement. After the micro-channel structure was adopted, the sensible and latent heat transfer capacity of the pulsating heat pipe was improved and the gross effect of the micro-channels greatly facilitated the reflux of condensate to the evaporation section, which could be regarded as the main reason why heat transfer was enhanced in the heat pipe. 
5.2.5 Thermal management system. Battery thermal management technology is of crucial significance for the development of new energy vehicles. A good thermal management system can guarantee the safe and efficient use of the battery. In the thermal management of the battery, it needs to be ensured that the battery temperature is within a safe temperature range and the maximum temperature difference in the battery pack will not exceed $5^{\circ} \mathrm{C}$. Alvani-Soltani pointed out that factors such as uneven temperature distribution or excessive temperature changes can cause damage and lose of control of the thermal of the battery in the early stage, and even cause accidents [53]. Therefore, the thermal safety issues of lithium-ion batteries limit their wide application in electric vehicles, and there is an urgent need for a thermal management system that can control and manage the thermal behavior of battery modules.

Zhang $\mathrm{G}$ et al. [54] adopted heat pipe cooling as the thermal management system of nickel-metal hydride battery, and compared it with the effect of air cooling. According to the results, heat pipe has a good cooling effect and can ensure that the battery runs within the best operating temperature range. Under the condition of $3728 \mathrm{~mA}$ current discharge, the heat pipe cooling reduces the battery temperature rise by about $10^{\circ} \mathrm{C}$ at most compared with air cooling. Zhong $\mathrm{H}$ et al. [55] cooled rectangular lithium batteries using flat heat pipes and found that for batteries with heating power less than $30 \mathrm{~W}$, flat heat pipes can not only control the battery temperature within $50^{\circ} \mathrm{C}$, but also keep the maximum temperature difference on the battery surface within $5^{\circ} \mathrm{C}$. For batteries with higher heating power, although the battery temperature can be controlled within $50^{\circ} \mathrm{C}$, the maximum temperature difference cannot meet the requirements. When the battery heating power is $50 \mathrm{~W}$, the maximum temperature difference of the system reaches $8^{\circ} \mathrm{C}$.

$\mathrm{Wu} \mathrm{M}$ et al. [56] used two heat pipes with aluminum fins to dissipate heat from lithium-ion batteries. In the experiment, the temperature of the battery was significantly reduced, and the temperature difference on the surface of the battery was greatly reduced. Jang et al. [57] conducted heat dissipation experiments on highpower batteries using a combination of loop-type gravity heat pipe and air cooling. Based on the results of the experiment, when water was used as the heat pipe working medium, the battery surface temperature was lower than $50^{\circ} \mathrm{C}$, while when acetone was used as the heat pipe working medium, the average temperature of the battery surface could be controlled at $45^{\circ} \mathrm{C}$. Jang et al. pointed out that the heat pipe was suitable for future EV (electric vehicle) and HEV (hybrid electric vehicle) battery thermal management.

Zhang W [58] studied the influence of the coupled heat dissipation of the tiny flat loop heat pipe and the phase change material on the maximum operating temperature and temperature distribution of the battery under the application background of the electric vehicle battery thermal management system. According to the results of the experiment, under the same placement and the same power conditions, when the micro loop heat pipe and the phase change material were coupled to dissipate heat, there was the longest time when the maximum temperature of the battery stays was below the upper limit of the optimal operating temperature $50^{\circ} \mathrm{C}$. The micro loop heat pipe system was second to it, with the shortest natural air cooling system. The safe working time of the same heat dissipation system, under the same power is longer when placed vertically than horizontally. Hu X [59] dissipated the cylindrical lithium-ion battery with the high-speed air flowing during the driving of the car using inorganic superconducting tubes, and conducted experiments on the inorganic superconducting tubes to cool the battery under the conditions of $5 \mathrm{~A}, 7.5 \mathrm{~A}, 10 \mathrm{~A}$ and so on. The maximum temperature of the battery surface did not exceed $50^{\circ} \mathrm{C}$, and the different effects of air-cooled forced heat dissipation and natural convection heat dissipation were compared, which proved the feasibility of the heat dissipation effect of the inorganic superconducting heat pipe heat dissipation system. In addition, the simulation results of the designed model using Fluent are greatly consistent with the experimental results. In order to understand the performance of the phase change material/heat pipe (PCM/HP) coupled cylindrical power battery thermal management system, Zhao J et al. [60] designed a PCM/HP coupled BTM module and conducted experimental tests. The results of which showed that, the temperature control effect based on PCM improved greatly compared with air-based BTM under natural convection conditions.

Starts from the heat dissipation capacity, the impact of the thermal management system on the battery system or even the entire vehicle environment is less taken into consideration, which results in defects such as complex structure, excessive mass and volume in the existing thermal management system, which is bad for the design of battery box design and the layout of the battery box in the vehicle, and extra power is consumed by the complex and heavy system, and it is not suitable for the future development trend of automobile lightweight.

Therefore, several aspects such as reducing volume and mass, simplifying structure and installation, and reducing secondary energy consumption should be taken into consideration in the future research on thermal management systems for lithium-ion power batteries. The specific measures recommended are as follows.

- Develop ultra-thin heat pipe technology. The ultra-thin heat pipe can be in close contact with the battery, while reducing the volume and mass, making the entire battery module compact, which is convenient for the design and installation of the whole vehicle.

- Develop heat pipe technology in which ultra-thin heat pipes and phase change materials are coupled. Taking advantage of latent heat storage characteristics of phase change materials, the heat capacity of the thermal management system can be increased after coupling with ultra-thin heat pipes can, which enables heat dissipation at high temperatures and heat preservation at low temperatures, and ensures that the battery always work in a reasonable temperature range. 


\section{Conclusion}

Heat pipe is an efficient heat transfer element. The focus of heat pipe technology research has shifted from theoretical research to application, and the application has shifted from aerospace to the ground, and from industrious to civilian use. At present, heat pipes have achieved good results in solar energy utilization, laptop CPU cooling, high-power transistor cooling, chemical engineering, metallurgy, power and so on. The application of heat pipes in these fields will further promote the development of new heat pipe technologies. Simultaneously, there are still a lot of problems and challenges existing. The traditional structure is single, the complex new wick is difficult to process, the theoretical mechanism of nanofluid is insufficient, and the actual preparation is difficult. However, the optimization of specific parameters mainly depends on experiment, and the simulation and analytical results are not the same. In the future, we need to work hard from the following perspectives.

- Taking the form of integrated heat pipe heat dissipation as an example, the radiator with a new concept layout structure design needs to be developed and studied in depth.

- The establishment of the theoretical model of nanofluids, the analysis of mechanism and the summary of heat transfer characteristics, and the preparation of stable nanofluids.

- Seek reasonable processing and forming techniques for composite liquid sucking wicks.

- The development of reliable and general analysis of thermal performance and parameter optimization methods is also the research direction in the future.

\section{References}

1. Chen C. (2005) Measuring the movement of a research paradigm. Proceedings of Spie the International Society for Optical Engineering, 5669:63-76.

2. Lin D, Chen C, Liu Z. (2011) Study on Zipf-Pareto Distribution of the Betweenness Centrality of a Cocitation Network. Journal Of The China Society For Scientific And Technical Information,30(1):76-82.

3. GROLL M, KHANDEKAR S. (2002) Pulsating heat pipes: A challenge and still unsolved problem in heat pipe science. Archives of Thermodynamics,23(4):1728.

4. KHANDEKAR S, GROLL M. (2004) Pulsating heat pipes: Attractive entrants in the family of closed twophase systems. J. Energy Heat Mass Transfer,26:99115 .

5. DEREK J D S P. (1965) Networks of Scientific Papers. Science, 149(3683):510-515.

6. Garfield E. (1994) Research fronts. Current Contents,41(10):3-7.

7. Chen C. (2006) CiteSpace II: Detecting and visualizing emerging trends and transient patterns in scientific literature. Journal of the American Society for Information Science and Technology, 57(3):359377 .

8. WANG S, HUO J, ZHANG X, et al. (2012) Experimental study on operating parameters of miniature loop heat pipe with flat evaporator. Applied Thermal Engineering, 40:318-325.

9. Hamdan M, Cytrynowicz D, Medis P, et al. (2002) Loop heat pipe (LHP) development by utilizing coherent porous silicon (CPS) wicks. In: Thermal \& Thermomechanical Phenomena in Electronic Systems. USA. pp.457-465.

10. ESARTE J, BLANCO J M, BERNARDINI A, et al. (2017) Optimizing the design of a two-phase cooling system loop heat pipe: Wick manufacturing with the 3D selective laser melting printing technique and prototype testing. Applied Thermal Engineering, 111:407-419.

11. WANG Y, CEN J, ZHU X, et al. (2012) Experimental study on the heat transfer performance of a loop heat pipe. Journal of Optoelectronics ' Laser, 08:1458-1462.

12. WANG D, LIU Z, SHEN J, et al. (2014) Experimental study of the loop heat pipe with a flat disk-shaped evaporator. Experimental Thermal and Fluid Science,57:157-164.

13. GAI D, LIU Z, LIU W, et al. (2009) Characteristics of temperature oscillation in miniature loop heat pipe with flat evaporator. CIESC Journal, 06:1390-1397.

14. Xue Q, JI X, Abanda A, et al. (2012) Heat Transfer Performance of Air Cooling Type Loop Heat Pipe With Compressed Foam Metal as Capillary Layers. Proceedings of the Chinese Society for Electrical Engineering, 32:58-63.

15. Riehl R R, Siqueira T C P A . (2006) Heat transport capability and compensation chamber influence in loop heat pipes performance. Applied Thermal Engineering, 26(11-12):1158-1168.

16. Santos P H D, Bazzo E, Oliveira A A M . (2012) Thermal performance and capillary limit of a ceramic wick applied to LHP and CPL. Applied Thermal Engineering, 41:92-103.

17. CELATA G P, CUMO M, FURRER M. (2010) Experimental tests of a stainless steel loop heat pipe with flat evaporator. Experimental Thermal and Fluid Science,34(7):866-878.

18. TANG Y, ZHOU R, LU L, et al. (2012) Anti-Gravity Loop-shaped heat pipe with graded pore-size wick. Applied Thermal Engineering,36:78-86.

19. Zhang H, Lin G, Cao J, et al. (2003) Groundexperimental study on the performance of Loop Heat Pipes. Journal Of Astronautics, 05:468-472.

20. [20] et al. (2007) Modulated wick heat pipe. International Journal of Heat and Mass Transfer,50(7):1420-1434.

21. YEH C, CHEN C, CHEN Y. (2009) Heat transfer analysis of a loop heat pipe with biporous wicks. International Journal of Heat and Mass Transfer,52(19):4426-4434.

22. SEMENIC T, CATTON I. (2009) Experimental study 
of biporous wicks for high heat flux applications. International Journal of Heat and Mass Transfer,52(21):5113-5121.

23. XU J, ZHANG L, XU H, et al. (2014) Experimental investigation and visual observation of loop heat pipes with two-layer composite wicks. International Journal of Heat and Mass Transfer, 72:378-387.

24. Li Q, Zhou H, Xuan Y. (2008)Investigation On Heat Transfer Characteristics Of Composite Capillary Evaporator. Journal Of Engineering Thermophysics, 01:148-150.

25. Xu J, Zou Y, Cheng L. (2012)Pore Structure Optimization and Properties of Composite Wicks for Loop Heat Pipes. Proceedings of the Chinese Society for Electrical Engineering, 23:70-74.

26. TONG B Y, WONG T N, OOI K T. (2001) Closedloop pulsating heat pipe. Applied Thermal Engineering, 21(18):1845-1862.

27. KHANDEKAR S, CHAROENSAWAN P, GROLL M, et al. (2003) Closed loop pulsating heat pipes Part B: visualization and semi-empirical modeling. Applied Thermal Engineering, 23(16):2021-2033.

28. ZHANG Y, FAGHRI A. (2002) Heat transfer in a pulsating heat pipe with open end. International Journal of Heat and Mass Transfer, 45(4):755-764.

29. Yang W, Zhang Z, Ma T. (2001) Flow visualization Of Looped Pulsating Heat Pipe.Journal Of Engineering Thermophysics,01:117-120.

30. Qu W, Ma T. (2002) Experimental Investigation On Flow And Heat Transfer Of Pulsating Heat Pipe. Journal Of Engineering Thermophysics, 05:596-598.

31. Yang H, Sameer K, Manfred G. (2007) Experimental Investigation of the Flow Patterns in a Single Closed Loop Pulsating Heat Pipe. Fluid Machinery, 01:60-63.

32. Cao X, Wang W, Chen J, et al. (2007) Experimental investigation on flow and heat transfer of pulsating heat pipe. Journal of Thermal Science And Technology, 01:56-59.

33. Xu R, Wang R, Cong W, et al. (2007) Design of Pulsating Heat Pipe Experiment Rig and Visual Experiment Study. Fluid Machinery, 06:59-61.

34. QU J, WU H, WANG Q. (2012) Experimental Investigation of Silicon-Based Micro-Pulsating Heat Pipe for Cooling Electronics. Nanoscale and Microscale Thermophysical Engineering, 16(1):3749.

35. Qu J, Wu H, Zheng P. (2010) Flow Visualization Of Silicon-based micro pulsating heat pipes. Sci China Tech Sci, 05:575-581.

36. Qu J, Wu H. (2011) Thermal performance of micro pulsating heat pipe. CIESC Journa, 11:3046-3052.

37. YOUN Y J, KIM S J. (2012) Fabrication and evaluation of a slicon-based micro pulsating heat spreader. Sensors and Actuators A: Physical, 174:189-197.

38. Choi, S.U.S. (1995) Enhancing Thermal Conductivity of Fluids with Nanoparticles. Proceedings of the
ASME International Mechanical Engineering Congress and Exposition, 66: 99-105.

39. WU J, ZHAO J. (2013) A review of nanofluid heat transfer and critical heat flux enhancementResearch gap to engineering application. Progress in Nuclear Energy,66:13-24.

40. LI X, SHI Z, WANG S, et al. (2012) Analysis of structural parameters of grooved-wicksin micro heat pipes based on capillary limits. Key Engineering Materials, 499: 21-26.

41. Y.M. Hung, SENG Q. (2011) Effects of geometric design on thermal performance of star-groove microheat pipes. International Journal of Heat and Mass Transfer,54(5):1198-1209.

42. HA J M, PETERSON G P. (1998) The Heat Transport Capacity of Micro Heat Pipes. Journal of Heat Transfer, 120(4):1064-1071.

43. SARTRE V, ZAGHDOUDI M C, LALLEMAND M. (2000) Effect of interfacial phenomena on evaporative heat transfer in micro heat pipes. International Journal of Thermal Sciences, 39(4):498504.

44. SUMAN B. (2008) Effects of a surface-tension gradient on the performance of a micro-grooved heat pipe: an analytical study. Microfluidics and Nanofluidics, 5(5):655.

45. GROVER G M, COTTER T P, ERICKSON G F. (1964) Structures of Very High Thermal Conductance. Journal of Applied Physics ,35(6):1990-1991.

46. C. G, Y. A, N. C, et al. (2003) Silicon heat pipes used as thermal spreaders. IEEE Transactions on Components and Packaging Technologies, 26(2):332339.

47. Liu Y, Liu H, Xiao H. (2009) The numerical simulation on heat transfer performance of rectangular micro channel plate heat pipe. Cryogenics And Superconductivtty, 03:40-44.

48. Wan Y, Yan K, Dong S, et al. (2015) Review on Flat Micro-heat Pipe Technology. Electro-Mechanical Engineering, 05:5-10.

49. Tang Q, Xu J, Li Y, et al. (2006) An Experimental Study of the Heat Transfer Performance of Innovative Micro Heat Pipes. Journal Of Engineering For Thermal Energy And Power, 04:350-354.

50. Fan C, Qu W, Sun F, et al. (2004) The Influence of Gravitation on the Heat Transfer Performance of Micro-grooved Flat-plate Heat Pipes. Journal Of Engineering For Thermal Energy And Power, 01:33-37.

51. LI W, LI J, Li Z, et al. (2017) Effect of Rectangle Micro-Grooves Structure on Heat Transfer Characteristics of Flat Heat Pipes. Journal of Engineering for Thermal Energy \& Power, 32(02):4246.

52. Li X, Qu J, Han X, et al. (2016) Start-up and heat transfer performance of micro-grooved oscillating heat pipe. CIESC Jorunal, 06:2263-2270. 
53. Alvani-Soltani S R, Ravigururajan T S, Rezac M. (2011) A critical review of thermal Issues in lithiumion batteries. Journal of the Electrochemical Society, 158(03): 1-25.

54. Zhang G, Wu Z, Rao Z, et al. (2009) Experimental invesitigation on heat pipe cooling effect for power battery. Chemical Industry and Engineering Progress, 07:1165-1168

55. RAO Z, WANG S, WU M, et al. (2013) Experimental investigation on thermal management of electric vehicle battery with heat pipe. Energy Conversion and Management, 65:92-97.

56. WU M, LIU K, WANG Y, et al. (2002) Heat dissipation design for lithium-ion batteries. Journal of Power Sources, 109(1):160-166.

57. Jang J, Rhi S H. (2010) Battery thermal management system of future electric vehicles with loop thermosyphon. In: US-Korea Conference on Science, Technology, and Entrepreneurship(UKC). New Jersey.

58. Zhang W. (2013) Research of miniature flat loop heat pipe on the heat dissipation of electric vehicle battery. South China University of Technology.

59. Hu X. (2012) Study on capacity of heat dissipation for Electric Vehicle Lithium ion battery based on inorganic superconductivity heat pipe. $\mathrm{Hu} \mathrm{Nan}$ University.

60. ZHAO J, LV P, RAO Z. (2017) Experimental study on the thermal management performance of phase change material coupled with heat pipe for cylindrical power battery pack. Experimental Thermal and Fluid Science, 82:182-188. 